\title{
Emo, eu? Reflexões sobre acusação na prática, escrita e pensamentos etnográficos.
}

Eduardo Fernandes ${ }^{1}$

\section{Resumo}

É cotidiano à prática do cientista comunicar o seu trabalho, publicando artigos e livros, apresentando em congressos e eventos, dialogando em sala de aula ou ambientes informais. Atualmente, quando falamos em etnografia, questionamentos sobre o teor das relações que envolvem o/a pesquisador/a, seus interlocutores e leitores são muito recorrentes. Sendo assim, cabe ao pesquisador estar atento a essas demandas e elaborar respostas. Neste pequeno ensaio, busco refletir complexamente momentos em que rotulações sobre o autor são acionadas para deduzir relações com suas pesquisas, a partir da minha atual pesquisa etnográfica com emos em na região metropolitana de São Paulo.

Palavras-chave: escrita etnográfica; acusação; autor; momentos etnográficos.

\begin{abstract}
It is customary in the scientist's practice to communicate his work, publishing articles and books, exhibiting at congresses and events, talk in the classroom or others environments. Nowadays, when we talk about ethnography, the content of relationships that involve researchers, their interlocutors and readers are very recurring in the questions addressed to the authors. Therefore, it is up to the researcher to be aware of these demands and be prepared to answer this kind of questions. On this essay, seeks to complexly reflect some moments that labelling about the author are driven to deduce relationships with your research, thinking my current ethnographic research with emos in São Paulo.
\end{abstract}

Keywords: etnography writing; accusation; author; ethnographic moments.

\footnotetext{
${ }^{1}$ Mestrando pelo Programa de Pós-Graduação em Ciências Sociais da Universidade Federal de São Paulo e membro do Grupo de Pesquisas Visuais e Urbanas (VISURB). Email: eduardofernandessoc@gmail.com
} 


\section{Emo, eu? Reflexões sobre acusação na prática e escrita etnográfica.}

\subsection{Pensando o texto etnográfico}

Durante minha trajetória como pesquisador em transformação, assim como qualquer outro que se dedique à carreira acadêmica, tive que apresentar minhas ideias frente à professores e aos meus pares. Seminários, apresentação de monografia de graduação, processo seletivo de ingresso na pós-graduação, comunicações orais em congressos e encontros. Seja para ser avaliado, seja para partilhar resultados, essas comunicações sempre são oportunidades de aprimoramento, pois além de treinarmos a forma como expomos e dialogamos nossas pesquisas com o mundo, também somos provocados e questionados, podendo responder à dúvidas ou ainda vislumbrar perspectivas que antes poderiam não ter nos ocorrido, pois nuances interpretativas são aspectos inerentes aos momentos que envolvem a escrita etnográfica.

Clifford Geertz (1989), em seu livro “A interpretação das Culturas” questiona até que ponto a escrita etnográfica não é um exercício de interpretação, aliás, de interpretação da interpretação dos nativos sobre as suas culturas. Para Geertz:

Como sistemas entrelaçados de signos interpretáveis [...] a cultura não é um poder, algo ao qual podem ser atribuídos casualmente os acontecimentos sociais, os comportamentos, as instituições ou os processos; ela é um contexto, algo dentro do qual eles podem ser descritos de forma inteligível - isto é, descritos com densidade (Geertz 1989: 24).

Como uma ciência interpretativa, a antropologia, segundo Geertz, teria o objetivo de apreender sistemas de significado ou estruturas significantes de forma tão densa que seria possível tornar inteligível os atos dos sujeitos dado um determinado contexto/cultura. Por atos, Geertz diz instituições, comportamentos, rituais, moda, enfim, tudo o que se faz e que é possível ser interpretado, analisado e descrito. Dessa forma, aquilo que os sujeitos dizem sobre si (não necessariamente pela fala), sobre a sua cultura, é como um texto que deve ser interpretado pelo etnógrafo, que por sua vez, elabora a sua própria interpretação sobre a interpretação que lhe foi dada. Trata-se de um exercício de tornar-se sensível à interpretação das miudezas e dos detalhes a partir do contato prolongado, promover uma análise e descrever de forma densa (Geertz 1989). O exercício etnográfico passa a ser um exercício semiótico de interpretação, passamos a assumir de forma irreversível a influência 
do autor como pessoa que realiza interpretações, análises e descrições que são sempre enviesadas. Esse exercício, por sua vez, é sempre parcial, mesmo que se trate de uma descrição extremamente densa, pois é sempre de segunda ou terceira mão, reformulações que podem ser submetidas à crítica autoral. Considerando essas colocações, passaremos ao debate contemporâneo na disciplina, onde questões como "de quem se fala" e "quem fala de quem se fala" adquirem certo protagonismo.

O próprio Geertz (2001) avalia o que ele chama de crise da etnografia como "reflexões incômodas sobre o envolvimento da pesquisa antropológica com os regimes coloniais, durante o auge do imperialismo ocidental, e com suas sombras de agora" (Geertz 2001: 91). Segundo o autor, houve no último século acusações por parte dos intelectuais do Terceiro Mundo sobre a cumplicidade dos intelectuais investigadores, "os que sabem”, com aqueles que implantaram os projetos de dominação colonial. Além disso, com pensadores como Derrida, Sartre e Foucault, houve também a crítica sobre o poder envolvido no discurso, principalmente sobre a representação do "outro" e da legitimidade que os etnógrafos, etnólogos, antropólogos e outros intelectuais teriam de "falar em nome deles". Segundo o autor, um bom posicionamento para pensar a nova situação da etnografia seria invocar posicionamentos mais críticos em relação ao texto etnográfico, criando um estado da produção do texto em que o autor deve se responsabilizar ainda mais.

O que Geertz (2001) classifica de crise da antropologia, Caldeira (1988), em seu texto “A presença do autor e a pós-modernidade em antropologia”, define como um processo de autocrítica pelo qual a antropologia passa. Em seu trabalho, a autora busca abordar alguns aspectos das mudanças do trabalho antropológico, sugerindo uma nova perspectiva crítica de reflexão sobre o papel do autor no texto etnográfico (Caldeira, 1988: 133). Segundo a autora, a crítica pós-colonial não implica somente no desvelamento das relações de poder presentes no texto antropológico, mas também se relaciona aos estilos de escritas e de críticas pós-modernas em antropologia (Caldeira 1988: 136). Caldeira também aborda a crítica americana pós-moderna a partir dos chamados “meta-etnógrafos” (Rabinow 1986, apud. Caldeira 1988: 135), que seriam aqueles etnógrafos que tomam como seu “outro" os textos etnográficos.

Caldeira defende que na antropologia a produção do conhecimento científico nunca esteve desatrelada da experiência do autor. O conhecimento antropológico é sempre baseado na experiência pessoal, pois o antropólogo é sempre ele mesmo produtor de dados, 
instrumento privilegiado de pesquisa. Segundo a autora, trabalhos como os de James Clifford, Marcus e Cushman, historiadores da disciplina, mostram a importância da fórmula "eu estive lá, vi e, portanto, posso falar sobre o outro" na trajetória da disciplina, construindo o que podemos chamar de autoridade etnográfica (Caldeira 1988: 134), peça fundamental da legitimidade construída pela disciplina vista em muitos trabalhos clássicos. Dialogando com o leitor, a partir de seu texto, o antropólogo do campo legitima a si mesmo pela confiabilidade que ele transmite, ele diz "você está lá, por que eu estive lá" (Clifford 1983: 118, apud. Caldeira 1988: 136).

De forma mais sintética, a autoridade etnográfica não só se legitima entre os pares, mas também se reifica na relação com o leitor e pela confiabilidade que ela transmite.

Segundo Marcus e Cushman (Marcus e Cushman 1982 apud. Caldeira 1988: 137), o chamado realismo etnográfico, um estilo literário holístico que busca representar mundos ou modos de viver totalizantes, é um estilo que historicamente retirou o etnógrafo do texto, por exemplo, não usando a voz em primeira pessoa no texto, na tentativa de garantir certa neutralidade, movimento paradoxal com a autoridade etnográfica explicada no parágrafo anterior. Se a autoridade etnográfica é fundada pela experiência pessoal de "ter estado lá", a busca da neutralidade que oculta o autor como sujeito trabalha no sentido oposto. Em outras palavras, para esses autores, houve um jogo de esconder e expor marcado ora pela tentativa de afirmação da autoridade, ora pela afirmação de neutralidade.

De forma sintética e partindo para o balanço necessário para este trabalho, há um certo movimento característico de muitas etnografias clássicas, criticado por autores póscoloniais e pós-modernos, que, além de ser de serem de certa forma autoritário, tende a "empobrecer" o texto no que diz respeito à elucidar formas de relações interpessoais. Em outras palavras, trata-se de movimentos de aproximação e de afastamento entre a cultura investigadora e aquela que é investigada, ou ainda, entre o etnógrafo e o nativo, criando limites muito bem delimitados com o objetivo de construir a autoridade etnográfica e a neutralidade. Dessa forma, o nativo é sempre um sujeito geral, sem grandes contradições, sem sentimento e até mesmo sem vida no texto.

Marilyn Strathern (2017) propõe que a etnografia deve evitar explicações totalizantes e que o seu escritor tem a obrigação epistemológica de refletir constantemente sobre as potencialidades e os limites de suas ferramentas analíticas, incluindo aqui o seu papel na 
escrita. Segundo a autora, no exercício etnográfico (1) escrevemos sobre complexidades e (2) com relação a momentos etnográficos.

A respeito das complexidades, Strathern define que todo o "sistema social"2 é composto por partes, sejam elas consideradas instituições, indivíduos ou qualquer outra definição. Quando justapomos diferentes ordens de dados, na coleta ou análise de informações, e explicitamos o método etnográfico, perceberemos que essas partes têm trajetórias que são próprias (Strathern 2017: 347). Em outras palavras, quando falamos de etnografias, devemos ter em mente que estamos falando de pesquisa com seres que são relativamente dependentes e relativamente independentes e que interagem de formas complexas não lineares. Sendo assim, não há como prever o todo ou os múltiplos resultados que a relação das partes desenvolverá ao longo da pesquisa antes que ela aconteça, considerando as influências de cada parte, mas também da parte que pesquisa, ou seja, o próprio pesquisador.

A escrita etnográfica, segundo Strathern não é de modo algum uma derivação ou um resíduo do trabalho de campo, em verdade, se constitui como um segundo campo, mantendo relações complexas com o primeiro, mas sem nunca se abrangerem ou se eliminarem em totalidade. O etnógrafo atua em locais alternantes, que oferecem perspectivas um sobre o outro. O momento etnográfico é um momento de imersão, total e parcial, como atividade totalizante que não é a única em que ele está envolvido (Strathern 2017: 345-346). O etnógrafo deve sempre ter em mente as orientações teóricas que o levaram a campo, o motivo de estar fazendo o trabalho, mas ao mesmo tempo sempre estar atento e aberto ao fluxo de eventos e às ideias que vão se apresentando, dessa forma, a pesquisa não se perde como um holismo absoluto em que tudo importa e onde se deve coletar e transcrever o máximo de dados possível, e ao mesmo tempo não ser uma pesquisa rígida que não esteja atenta à complexidade da vida. Quando "voltamos do campo" devemos inverter essas orientações, ou seja, considerar a escrita (o segundo campo) em relação ao (primeiro) campo, mas estando aberta às novas ideias e novos acontecimentos, mostrando também aquilo que perdeu-se ou que foi negligenciado (Strathern 2017: 346349).

\footnotetext{
2 A autora faz algumas considerações sobre as terminologias "sistema" e "dados", dizendo que não se aterá muito a esse debate. Uso esses termos para respeitar o que o texto diz.
} 
O direcionamento que se tem é o de que devemos mostrar quais são os momentos em que a nossa atenção é petrificada na relação complexa entre os dois campos. Além disso, reconhecer que não sabemos de tudo de antemão e que isso enriquece o trabalho, pois mostra que estamos construindo saberes que consideram a complexidade e a surpresa.

\subsection{Quem fala sobre quem?}

No cotidiano da pós-graduação somos provocados a comunicar nossas pesquisas. Em muitas dessas oportunidades, se nos mantermos atentos, poderemos nos deparar com perspectivas diversas, sejam saberes mais acadêmicos quanto experiências em sentido amplo. Ao comunicar minha atual pesquisa em uma disciplina do Programa de Pósgraduação em Ciências Sociais, que tinha como objetivo promover espaços de discussão sobre os projetos de pesquisa dos ingressantes do mesmo, me deparei com um momento que se tornou pivô para um remodelamento da minha perspectiva como autor. Após a minha apresentação, que passou por questões teórico metodológicas, mas também sobre informações adquiridas a partir do "pré-campo", uma colega de turma se mostrou empolgada com a minha pesquisa.

Essa colega, que tem aproximadamente a mesma idade que eu (atuais vinte e oito anos), ao comentar sobre meu projeto se ateve à sua própria experiência no rolể emocore/alternativo, mais especificamente no rolê do Bocage 4 . Em seu comentário/depoimento contou ter sido frequentadora assídua do point, que costumava sair para beber com os frequentadores do rolê e sobre como o encontro atraía muita gente, a ponto de encher a rua. Falou também sobre a estética visual que as pessoas ostentavam e o prestígio vinculado a ele, lembrando que quem tinha uma aparência mais carregada, isto é, quem vestia as melhores roupas, um tênis específico, tatuagens, piercings e outros, era tido como "famoso". Naquele momento, fiquei empolgado e surpreso a ponto de sentir necessidade de conversar com essa colega mais algumas vezes sobre o assunto, pois estava tendo contato com potenciais informações para a minha pesquisa. Quem diria que num

\footnotetext{
3 Rolê é uma atividade de lazer que indica trânsito pela cidade.

4 O rolê acontecia próximo ao bar de mesmo nome e se espalhava pela Alameda Itu, pelas imediações de outros aparelhos, como o clube Plastic Dreams, onde acontecia a festa Orgástica e o Sativas (entre Avenida Rebouças e Rua Bela Cintra). Próximos à estação do Metrô da Consolação (não existia a estação Paulista na época).
} 
espaço que, a princípio, estaríamos discutindo "a forma" do projeto de ter contato com alguma potencial interlocutora?

Alguns meses depois, participei da XIII Reunião de Antropologia do Mercosul (RAM), importante evento que reuniu diversos pesquisadores de antropologias do sul mundial, no projeto de debatermos, partilharmos e produzirmos conhecimento, onde apresentei um trabalho intitulado "Cena emo: práticas de juventude e táticas de resistência em São Paulo". No meu trabalho analiso como os emos elaboraram táticas de resistência frente às estratégias de normalização no cotidiano da cidade. Passando desde a padronização comportamental imposta pelos roqueiros da Galeria do Rock até os conflitos com moradores do mesmo rolê do Bocage e com a polícia no exercício do direito de ocupação do espaço público, compondo, assim, o Grupo de Trabalho "Culturas juvenis de rua no século XXI: transgressão, criatividade e resistência”.

No segundo dia de comunicações, após a apresentação do meu trabalho e os de outros colegas, as pessoas que compareceram, tanto ouvintes quanto expositores, tiveram a oportunidade de tecer comentários mútuos. Os questionamentos dirigidos a mim passaram pela maneira como conduzi as entrevistas, como tive acesso aos perfis de alguns dos meus interlocutores na extinta rede social Orkut, como venho trabalhando o conceito de cena alternativa, como o termo alternativo pode se relacionar à teoria da rotulação e sobre como a minha própria experiência teria relação com a pesquisa, seja pela minha presença em campo, seja por experiências anteriores com meus interlocutores no rolế Uma colega, também aproximadamente da mesma idade que eu, ao fazer seu comentário sobre o meu trabalho, relatou identificar-se com ele, pois ela própria tinha sido emo e frequentado os rolês que aconteciam na cidade de Porto Alegre, Rio Grande do Sul. Contou um pouco sobre onde e como aconteciam os rolês. O texto que apresentei, que buscava explorar as questões de acusação, rotulação e penalização de jovens emos, dialogava com as suas próprias experiências, pois também tinha sofrido represálias, tanto na rua quanto em casa, por ter sido emo.

Ambos os momentos de onde foram realizados comentários e depoimentos, numa primeira concepção, poderiam se assemelhar como oportunidades de exposição ou de

\footnotetext{
${ }^{5}$ As falas sobre as experiências dos etnógrafos em seus campos apareceram em outras colocações também, como nos comentários do professor Alexandre Pereira sobre as implicações de ser um pesquisador mais velho que estuda juventudes e de colegas mulheres que problematizaram a presença feminina no campo das juventudes e suas implicações, muito caracterizado pela investigação de práticas de homens/garotos no espaço público.
} 
debate teórico, mas, com o decorrer dos acontecimentos, tornaram-se momentos de diálogo com interlocutores, ou ainda, momentos etnográficos (Strathern, 2017). Ademais, esses momentos me proporcionaram a oportunidade de refletir como a minha pesquisa me liga às pessoas de diversas maneiras, dentro e fora da academia. Essas relações não se limitam apenas às questões teórico-metodológicas, mas se expandem as nossas próprias experiências num sentido amplo. Ou ainda, como questões teórico-metodológicas não são apartadas totalmente da vida, que inclui também a academia. Toda uma nova geração de graduados e pós-graduandos que foram emos ou viveram o emo (seja como participantes ou “espectadores") está ocupando os bancos da academia e acredito que momentos como estes ainda se repetirão por várias vezes na minha trajetória acadêmica. Este mesmo tipo de reflexão pode ser feito para outras pesquisas a depender da forma como o autor lida com as questões identificação e visibilidade.

A partir destes diálogos entre os momentos etnográficos e em vários espaços, passei a me questionar sobre como construir um lugar para mim em meus textos. Que lugar seria esse, como poderia enriquecer meu trabalho e, ao mesmo, tempo responder às questões importantes no campo da escrita etnográfica?

\subsection{Emo e não-emo, algumas respostas.}

Era meu primeiro dia de aula no Ensino Médio em 2005. Fazia pouco mais de uma semana que estava morando na casa da minha avó paterna e me sentia como um estrangeiro no bairro e nas duas escolas novas, de ensino regular e do ensino profissionalizante. Durante o intervalo de aulas no Ensino Médio me sentia totalmente deslocado, com um sentimento de não pertencimento e medo de não conseguir fazer amizades. Provavelmente, naquela manhã, eu deveria estar calçando um par de All Stars, usando camiseta preta lisa, jeans rasgados, cabelo tingido de vermelho e arrepiado com glicerina. Costumava dizer que me identificava como gótico ou dark e ouvia músicas de bandas como Lacuna Coil, Evanescence, Depeche Mode e Nightwish. Surpreendentemente, duas garotas se aproximaram de mim dizendo com entusiasmo que tinham adorado a minha maneira de vestir e que, a partir

\footnotetext{
${ }^{6}$ Gótico ou dark é um movimento cultural jovem urbano que surgiu em São Paulo a partir da segunda metade da década de 1980, como uma faceta mais soturna do rock.
} 
daquele momento, seríamos da mesma turma. Eram primas e se assemelhavam comigo na forma de vestir no que se referia ao uso de alguns acessórios como cintos com pinos, pulseiras com espetos, piercings e a roupa preta, mas, diferentemente de mim, elas se identificavam como emos e usavam cabelos com franja tapando um dos olhos, mechas coloridas e presilhas, camisetas, que apesar de escuras, tinham estampas "fofas", maquiagem intensa e se comportavam de um jeito mais empolgado e infantilizado. Foi pelo contato com essas amigas que fui aprendendo o que eram os/as emos e seu jeito de viver. Não demorou muito para eu conhecer outros emos e roqueiros de todo o tipo com quem fiz amizade e formava uma turminha. A maioria de nós estava descobrindo formas diversas de estar no mundo, quanto ao estilo e gosto musical, sexualidade e outros comportamentos.

Andando com essa nova turma na escola, ostentando um certo visual que poderia se assemelhar com o emo, notei que fui rotulado, aos poucos, e tratado como um. Era comum no cotidiano de um emo ser caçoado e até mesmo apanhar. Andando com os meus amigos pelos corredores eu ouvia frases como "todo emo é poser", "todo emo é gay", "se você anda com os emos, você também é um". Para evitar ser caçoado, costumava negar enfaticamente ser um emo, usando principalmente a justificativa de que o som que eu ouvia era outro e que meu visual era diferente. Frequentei aquela escola por menos de 6 meses, pois consegui um estágio na indústria.

Durante os próximos anos, o estilo emocore estouraria na grande mídia, arrastando milhares de fãs aos shows, festivais e encontros de rua. Sua música e suas imagens eram partilhadas nas rádios, na televisão, nas revistas. Em uma velocidade digna da internet, o emocore emergiu do underground e passou a ter visibilidade pública, tornando-se um rótulo comum na boca dos adolescentes.

Segundo Erwing Goffman (2008), os diferentes grupos criam modelos de categorias que servem para rotular os indivíduos, levando em conta certos atributos primeiros. Ou seja, existe uma imagem externa ao indivíduo que possibilita a leitura e a dedução de uma identidade social virtual, inferências dedutivas e generalizantes, que podem corresponder com a realidade ou não. Aquilo que se pode comprovar como de fato atributos do indivíduo chama-se identidade social real. As diferenças entre identidade social virtual e identidade social real interessam ao autor como maneiras de compreender como as relações entre

\footnotetext{
${ }^{7}$ Do inglês. Poser é um sujeito que apenas posa/simula ser alguma coisa. Que usa de um visual para esconder a sua "verdadeira identidade".
} 
expectativa e realidade podem gerar o problema do estigma. O que temos é que a inferência negativa de uma identidade social virtual sobre uma identidade social real, o estigma, têm por consequência acomodar pessoas ao estado de "desqualificação", da deficiência ou de certo desprestígio. Por outro lado, quando a inferência de uma identidade social virtual sobre uma identidade social real é positiva, temos o símbolo do prestígio. Estigma, por sua vez, se divide em três espécies: deformidades físicas, culpas de caráter, e por fim, atributos de raça/etnia, nação e religião. A partir dessas colocações, poderia dizer que por muitas vezes fui rotulado como emo para que fosse aceitável ser caçoado e que não adiantava eu negar o rótulo, pois o estigma e seus efeitos dependem sempre de acusações, de como as pessoas te denominam e, no caso do emo, o estigma tinha uma qualidade contagiante, pois bastava ser amigo de um e/ou parecer com e você seria tratado como um. "Diga com quem tu andas, que direi quem tu és", era uma frase que eu ouvia frequentemente dos estigmatizadores.

Anos mais tarde, já na graduação em Ciências Sociais, etnografei junto com colegas o cotidiano de artistas rotulados como "hippies" em Uberlândia, Minas Gerais. Sujeitos que, após o trabalho de pesquisa, demonstraram ter visões de mundo e relações que se constituíam, através de seus trabalhos artísticos, muito diferentes da juventude anticapitalista, antibelicista e psicodélica dos Estados Unidos das décadas de 1960-70. Desde a graduação, tenho me interessado pelo estudo de práticas artísticas, cidade e rotulação e essas também são trajetórias possíveis de serem feitas na compreensão da minha relação com a minha pesquisa atual com os emos na Região Metropolitana de São Paulo.

Conforme fui tendo mais contato com as teorias do desvio e de estudo da cidade, comecei a ter algumas ideias, momentos de conexão entre experiência e leitura, sobre alguns episódios da minha adolescência. Pensava em como seria interessante investigar de forma mais criteriosa as práticas emos em São Paulo na primeira década dos anos 2000 como minha monografia de graduação. Aprofundando a investigação, me deparei com a dissertação de mestrado de Raphael Bispo (2009), "Jovens Werthers", onde o autor explora, a partir de uma perspectiva etnográfica e voltada a antropologia das emoções, o contato que teve com uma turma de emos da cidade do Rio de Janeiro que se encontravam no Parque da Quinta da Boa Vista, se relacionavam muito pela internet e eram famosos na escola. O grupo se autointitulava Realeza e era em sua maioria de emos adolescentes, meninos e meninas. Exceto por Hematoma, ele era um "não-emo", um sujeito que não se 
identificava como emo, mas que se associava com o resto da turma pela amizade, pela frequência nos rolês, pela sexualidade desviante, mas principalmente pela postura ultrarromântica. Assim como Hematoma, eu era um não-emo que poderia ser identificado com eles por muitas questões, com exceção de certas diferenças no visual (que poderiam não ser drásticas a ponto de serem consideradas por outros) e, principalmente, a autoidentificação.

Escrevi a minha monografia de graduação dialogando com os emos, mas ainda utilizando uma linguagem em terceira pessoa e um tanto distanciada. Pensava, pela força da disciplina, incutida desde os tempos do Ensino Fundamental, que o tipo de escrita que nos distancia de nossos "objetos de estudo" teria mais legitimidade científica. Mesmo reproduzindo trechos de falas de alguns emos que entrevistei, não construí um lugar crítico sobre a minha posição como autor. Aqui, temos novamente o movimento de distanciamento e aproximação típico dos escritos clássicos em etnografias, assim como relatado por Caldeira. $\mathrm{Na}$ minha concepção, influenciado pela doxa da neutralidade ainda muito presente nos mais diversos espaços de comunicação da ciência, pensava que um texto bem avaliado deveria ser aquele que me colocava como um sujeito sem corpo, uma entidade intelectual imparcial que se relacionava apenas com "fatos e evidências". Ou, de certa forma, não queria sofrer acusações de que eu, como sujeito que estava construindo ciência, estaria me misturando com meu "objeto" de pesquisa.

Conforme fui sendo questionado em vários momentos, em espaços acadêmicos, em leituras e também por mim mesmo, sobre minha presença no texto e as relações que mantenho com os meus interlocutores, percebi como esta apresentação de mim no espaço público demanda uma profunda reflexão. Desse exercício surgem alguns questionamentos: como me posicionar no texto elaborando um lugar para mim em minha pesquisa e, ao mesmo tempo, diminuir as chances de ser estigmatizado? Como apresentar uma identidade social real, como um autor em transformação que pensa complexa e criticamente limites éticos, teóricos e metodológicos? Pensando esses questionamentos, comecei a elaborar algumas respostas considerando o exame de possibilidades de estigmatização perante apresentações de lugares de escrita.

Por muitas vezes, as identidades sociais virtuais que se inferem sobre pesquisadores e suas relações com seus interlocutores ou temas de pesquisa podem gerar processos de 
estigmatização do tipo que se aproxima a culpa de caráter em duas modulações extremas: uma que defende o afastamento e o outra que defende o envolvimento acima de tudo.

Se numa primeira perspectiva, que de certa forma eu considerava como um dos meus pontos de partida, pesquisadores não deveriam se envolver nem pertencer ao grupo de pesquisados, pois poderiam ser acusados de macularem o distanciamento necessário ao ideal da neutralidade, em outras perspectivas, pelo contrário, sinais que podem ser lidos como indicativos de não pertencimentos são totalmente reprovável. No segundo caso, que é o inverso do primeiro, o estigma se caracteriza a partir da inferência de que um pesquisador, ao ser lido como não pertencente a um determinado grupo, não seria apto a realizar um estudo válido. Em casos extremos, esse segundo quadro é bom para pensar algumas perspectivas pós-modernas que valorizem, acima de qualquer coisa, a legitimidade do discurso experiencial frente a deslegitimação do estudo por um indivíduo "externo". Afirmações como "só se pode falar se você parece ser" ou "quem não parece ser não pode falar sobre" são alguns exemplos da perspectiva em que a aparência de pertencimento é algo obrigatório e que também traz problemas.

Vale dizer que as leituras dos primeiros sinais e as deduções decorrentes dela nada mais são que leituras superficiais, que podem ser feitas a partir de atributos físicos, de comentários de terceiros ou até mesmo a partir de leituras rasas da obra de um determinado autor. Também podemos pensar que os sinais emitidos podem ou não serem manipulados pelo autor em questão, sua intenção de apresenta-los sua desatenção em especifica-los e suas escolhas de referenciais que prezem ou não pelo envolvimento. Substituindo o estigma pelo símbolo de prestígio temos os mesmos quadros de forma invertida, isto é, são valorizadas as identidades sociais que correspondam as perspectivas esperadas em cada campo, afastamento ou identificação com a pesquisa. Em alguns momentos fui confrontando em pensar se me construindo um lugar de extrema identificação com os emos poderia significar alguma facilidade absoluta na pesquisa, pois poderia significar $\mathrm{m}$ um fictício acesso facilitado em todos os momentos e a todas as informações. Essas são afirmações superficiais que não correspondem à realidade dos acontecimentos e as contradições que nos surpreendem em campo, tanto no que se refere à presunção de identidades, quanto às relações que estabelecemos com nossos interlocutores.

Complexificando um pouco mais, podemos pensar também como os cruzamentos entre rotulações e comportamento efetivamente reivindicado produzem duas espécies de 
híbridos. Em "Outsiders”, Howard Becker (2008) discorre sobre o desvio como uma categoria que é uma consequência da acusação e da rotulação, ou seja, o desvio é uma qualidade atribuída a certos atos e está sempre ligada ao conceito de comportamento aceito ou de normalidade vigente num grupo. Dessa forma, só é desviante aquele que foi detectado e rotulado. Contudo, existem entre os desviantes aqueles que são falsamente acusados e aqueles que são os desviantes ocultos, dois tipos de híbridos resultados dos cruzamentos entre rotulação e comportamento comprovável. No primeiro caso, aquele que é acusado, na verdade não corresponde ao comportamento que lhe é atribuído, como na condição de uma pessoa que era acusada de ser emo, sem realmente ser. No segundo caso, alguém que verdadeiramente se comporta de forma desviante, mas nunca foi rotulado, como na condição de um emo que conseguia, mesmo que em certos momentos, ocultar a sua "verdadeira identidade".

Trabalhando com esses híbridos, podemos apontar o agravamento do problema que são as inferências sobre o envolvimento do autor e sua classificação a partir de leituras superficiais. Poderíamos ter um etnógrafo que é lido e classificado como "nativo", mas que pouco se envolveu com a pesquisa. Poderíamos ter um pesquisador que presa pela neutralidade e o afastamento, mas que na realidade é extremamente envolvido e teve de ocultar este envolvimento para ser tido como "respeitável" na ortodoxia acadêmica. Poderíamos ter outro pesquisador que se envolveu muito em sua pesquisa, que viveu junto durante anos, mas que, por carregar certos sinais, poderia ser lido, por alguns, como "totalmente de fora" e acusado como alguém que nunca saberia o que sabe, que teria forjado ou roubado ideias dos seus interlocutores, um colonizador do saber. Enfim, o que estamos pensando é como o caso da leitura, inferência e classificação do etnógrafo como próximo ou distante dos seus interlocutores e/ou causa que estuda, a partir de certos sinais primeiros, pode resultar em injustiças ou erros interpretativos graves e como esses posicionamentos se relacionam com o modelo do ideal da neutralidade, que busca o afastamento como um fator de preservação da pesquisa "sem influências do autor", ou ele ás avessas, onde se persegue a experiência estrita como único lugar de fala legítimo.

Em todos os casos, concretos e abstratos, estou discutindo sobre possíveis leituras que podem ser feitas sobre as relações entre pesquisadores e suas pesquisas, de acordo com certos sinais, que podem indicar envolvimento ou afastamento, e como essas impressões se relacionam com disputas no campo da etnografia. Evitando extremismos, sugiro o exercício 
tático de desvelamento do envolvimento em suas pesquisas, em que os autores tenham consciência das possíveis leituras, interpretações e implicações de sua obra, e que, como estou tentando fazer, possam articula-las para construir reflexões que falem do próprio exercício de pesquisar, escrever, expor e dialogar. Enfim, reflexões sobre pensamento e prática de um cientista social em transformação.

Junto ao comportamento que não corresponde a virilidade heteronormativa, carrego no meu corpo alguns sinais diacríticos que me remetem aos momentos em que estive com os emos: alargadores, tatuagem visível no antebraço, estilo de vestir que remete ao rock: camisetas escuras estampadas, jeans, tênis de skate ou botas. Tendo passado mais de dez anos dos primeiros contatos, provocado pela memória de meus interlocutores através de seus depoimentos, revisito minhas experiências junto aos emos. Carrego comigo os momentos divertidos de cabular aula no ginásio da escola ouvindo as músicas de rock que tínhamos em nossos aparelhos de MP3, mas também as violências que passamos juntos, de sermos chamados de "posers" e "veados" nos corredores da escola e de fugir de "punks" na Rua Augusta.

Raphael Bispo encerra sua dissertação ironizando a posição de Hematoma em enfatizar ser um não-emo, apesar de partilhar muitas experiências e características com eles. "Hematoma, emo? Imagina...." (BISPO, op. cit.: 246). Se, como diz o autor, o emo é um movimento que "não ousa dizer o seu nome"8 (ibidem: 21), me questiono até que ponto a necessidade de ter que negar ter sido um, na época da escola, pode ter influenciado quem sou hoje e o tipo de ciência que produzo? Caso não tivesse sofrido as violências mencionadas, teria eu um dia adotado a denominação emo? Se tudo não tivesse acontecido como foi, teria eu me interessado pelos estudos de estigmatização, desvio e juventudes? As respostas para essas perguntas podem ser muitas e passíveis de críticas. As possibilidades articuladas neste texto não têm a intenção de formular uma única resposta bem-acabada, pois, talvez, eu mesmo esteja caminhando entre o ser e o não ser emo desde os tempos da escola.

Afinal, ter sido emo ou não, não significa que o que escrevo seja algo como um desabafo, autocentrado, que só diz sobre mim e sobre os meus. Assim como, ser identificado ou não como um emo, também não acrescenta por si só um símbolo de

\footnotetext{
${ }^{8}$ Citando Jim Derogatis em matéria publicada no portal Guitar World em 1999.
} 
prestígio ou um estigma na minha posição como pesquisador. Entretanto, nem por isso devo simplesmente desconsiderar o que vivi com eles, caindo assim em outra armadilha. É interessante conceber que estes arranjos são bons para repensar complexamente a apresentação de si, nos mais diversos momentos, e como ela é sempre atravessada por relações que estabelecemos com "outros" durante nossas vidas, inclusive enquanto momentos de leituras, de escrita e de diálogo de nossas pesquisas em sentidos amplos. O empreendimento etnográfico a que tenho me proposto é construído a partir de reflexões sobre as tensões e transformações específicas provocadas pelo próprio exercício da escrita etnográfica.

Como ressaltado por Gilberto Velho, refletindo Da Matta e Simmel, aqueles que se dedicam a desenvolver estudos com os que estão próximos devem estar atentos as diferenças e similaridades, pois podemos até falar a mesma língua, partilhar o mesmo vocabulário, viver na mesma cidade e ter experiências similares, mas temos interpretações diferentes sobre o mundo, e que familiaridades e exotismos fazem parte da dinâmica da construção do conhecimento e do desconhecimento. "O que sempre vemos e encontramos pode ser familiar, mas não é necessariamente conhecido e o que não vemos e encontramos pode ser exótico, mas até certo ponto conhecido" (VELHO, 2008: 127). Ou seja, entre o meu universo e o universo dos meus interlocutores há uma série de continuidades e descontinuidades a serem exploradas. O fato de possuirmos em comunhão certos aspectos nas trajetórias de vida não facilitam de forma absoluta o estudo, pelo contrário, implica em precauções e responsabilidades.

Com o decorrer da pesquisa, fui percebendo como a investigação criteriosa que abordasse várias visões, suas confluências e contradições, foi transformando a minha visão sobre os emos: momentos que pensava haver muita importância se tornaram não tão relevantes e momentos que eu achava insignificantes passaram a ser importantes. Pessoas com as quais não tinha tido contato passaram a me revelar intimidades e pessoas que eu pensava conhecer bem revelaram outras camadas de si. Enfim, os contatos com outras perspectivas produziram profundas transformações em mim e produziram um novo tipo de perspectiva que é múltipla. Dito isso, o contato anterior com alguns de meus interlocutores também não me coloca em uma posição de apenas vantagens, pelo contrário, em alguns momentos esse contato é um problema, por exemplo, quando tento marcar entrevistas e buscar informações que, ao ver da pessoa, poderia comprometê-la com 
conhecidos em comum. Por vezes, tenho dificuldade de explicitar meu posicionamento como pesquisador e fazer com que alguns de meus interlocutores entendam que se trata de uma tarefa séria de produção de conhecimento. Enfim, acontecimentos que complexificam a pesquisa e a enriquecem pois demonstram vitalidade (minha e de meus interlocutores).

\section{Considerações finais}

Partindo para um fechamento provisório, primeiramente esse texto buscou relacionar episódios em espaços acadêmicos como momentos etnográficos, demonstrando como gabinete e campo não estão afastados quando estamos abertos aos acontecimentos da vida. Mais adiante, refleti sobre os primeiros contatos e como vivi com alguns emos na época do Ensino Médio, nossas proximidades e distanciamentos e como essas experiências atravessam a pesquisa etnográfica que desenvolvo. O que se quer defender, portanto, é que as pessoas com quem encontramos podem enriquecer nossas pesquisas, de forma a refletirmos não apenas informações relacionadas diretamente às nossas investigações e práticas em sentido estrito, mas oportunidades de refletir a própria teoria etnográfica e o lugar que o autor constrói para si no texto.

Assim, se um dos lemas de certa antropologia, como a defendida por Geertz, é o da descrição densa, esse pequeno estudo buscou ser um exercício de articular este mote, descrevendo densamente algumas escolhas e o meu envolvimento com as pessoas que encontro durante a pesquisa nos mais diversos níveis. Este tipo de exercício próprio da etnografia, assim como defende Strathern, abriu possibilidades para que eu pudesse sofrer transformações e, como autor, produzir reflexões complexas e férteis que sejam sinceras e respeitosas com aqueles com quem estabeleço contato, sejam interlocutores ou leitores.

\section{Referências}

BECKER, Howard. Outsiders: Estudos de Sociologia do Desvio. Rio de Janeiro: Zahar, 2008.

BISPO, Raphael. Jovens Werthers: Antropologia dos Amores e Sensibilidades no mundo Emo. Rio de

Janeiro: UFRJ/ Museu Nacional/ PPGAS, 2009.

CALDEIRA, Teresa. 1988. A presença do autor e a pós-modernidade em antropologia. Novos Estudos - v. 21, p. 133-157. São Paulo: CEBRAP, 1988. 
GEERTZ, Clifford. A interpretação das culturas. Rio de Janeiro: Zahar, 1989.

. Nova luz sobre a antropologia. Tradução de Vera Ribeiro. Rio de Janeiro: Jorge Zahar, 2001.

GOFFMAN, Erving. Estigma: notas sobre a manipulação da identidade deteriorada. Rio de Janeiro: LTC, 2008.
STRATHERN, Marilyin. O efeito etnográfico. São Paulo: Ubu,2017.

VELHO, Gilberto. Individualismo e Cultura: notas para uma antropologia da sociedade contemporânea. Rio de Janeiro: Jorge Zahar, 2008. 